\title{
Comparison of Transforaminal and Parasagittal Epidural Steroid Injections in Patients With Radicular Low Back Pain
}

\author{
Seyed Masoud Hashemi ${ }^{1}$; Mohamad Reza Aryani ${ }^{2,} ;$ Sirus Momenzadeh $^{2}$; Seyed Sajad Razavi ${ }^{2}$; \\ Gholamreza Mohseni ${ }^{2}$; Seyed Amir Mohajerani ${ }^{2}$; Ali Akbar Esmilijah ${ }^{3}$ \\ ${ }^{1}$ Department of Anesthesiology, Akhtar Hospital, Shahid Beheshti University of Medical Sciences, Tehran, Iran \\ 2 Department of Anesthesiology, Shahid Beheshti University of Medical Sciences, Tehran, Iran \\ ${ }^{3}$ Department of Orthopedics Surgery, Shahid Beheshti University of Medical Sciences, Tehran, Iran \\ ${ }^{*}$ Corresponding author: Mohamad Reza Aryani, Department of Anesthesiology, Shahid Beheshti University of Medical Sciences, Tehran, Iran. Tel/Fax: +98-2122612252, \\ E-mail: Dr_aryani@yahoo.com
}

Received: January 5, 2015; Revised: February 11, 2015; Accepted: March 18, 2015

\begin{abstract}
Background: Epidural steroid injection (ESI), including transforaminal (TF) epidural injections and interlaminar (IL) epidural steroid injections are commonly performed procedures for the management of lumbosacral radicular pain. Parasagittal interlaminar (PIL) approach could enable higher ventral epidural spread, with fewer complications than TF.

Objectives: This study aims to compare the effectiveness of PIL and TF ESI in relieving the pain and disability of patients with lumbosacral pain.

Patients and Methods: This prospective study enrolled 64 patients, aged between 18 to 75 years, with a diagnosis of low back pain and unilateral lumbosacral radicular pain. The patients were randomized to receive fluoroscopically guided epidural injection, through either the PIL orTF approach. Patients were evaluated for effective pain relief [numerical rating scale (NRS) <3] by 0-10 numeric rating scale(NRS) and functional improvement by the Oswestry Disability Index (ODI).

Results: Effective pain relief [numeric rating scale (NRS) < 3] was observed in 77.3\% (95\% CI: 67-90.5\%) of patients in PIL group and 74.2\% (95\% CI: 62.4 -89.4\%) of patients in the TF group (P = 0.34), at 4 weeks. Mean NRS score was not significantly different between the PIL group compared to the TF group, at 4 weeks $(\mathrm{P}=0.19)$. Number of patients with improved disability (measured by ODI $<20 \%$ ) was not significantly different in PIL group ( $78 \%$ of cases) compared to the TF group ( $76 \%$ of cases), at 4 weeks $(P=0.21)$. There were no adverse effects observed in any of our patients.

Conclusions: The PIL epidural injection is as effective as TF epidural injection in improving pain and functional status, in patients with chronic lumbosacral low back pain, due to disc degeneration.
\end{abstract}

Keywords: Intralaminar Thalamic Nuclei; Low Back Pain; Transforaminal; Injections, Epidural; Steroid; Disability Evaluation

\section{Background}

Epidural steroid injection (ESI), including transforaminal (TF) epidural injections and interlaminar(IL) epidural steroid injections are commonly performed procedures for the management of lumbosacral radicular pain (1). Although both procedures are minimally invasive and effective (2), there is, however, lack of substantial evidence about the superior efficacy of one of these interventional approaches.

The IL epidural injection can be delivered through midline, paramedian, or parasagittal approaches (3). The TF entry can be directed more closely to the assumed site of pathology in the anterolateral (AL) epidural space, requiring less volume of injection than the IL route. Therefore, TF approach is considered more efficacious than the midline IL approach, probably due to better ventral epidural spread (4). In the meantime, the concerns regarding the safety of the TF approach lead to the search for a technically better route, with lesser complications in the IL approach.

The parasagittal interlaminar (PIL) route could induce higher ventral epidural spread, with fewer complications than TF (5). Although there is limited evidence in the literature showing the effectiveness of PIL in redirecting epidural injection to ventral space, however, it has not been thoroughly studied compared to the TF approach.

\section{Objectives}

This study aims to compare the effectiveness of PIL and TF ESI in relieving the pain and disability of patients with lumbosacral pain.

\section{Patients and Methods}

The study was reviewed and approved by the University Review Board of Shahid Beheshti University of Medi-

Copyright ( 2015, Iranian Society of Regional Anesthesia and Pain Medicine(ISRAPM).This is an open-access article distributed under the terms of the Creative Commons Attribution-NonCommercial 4.0 International License (http://creativecommons.org/licenses/by-nc/4.0/) which permits copy and redistribute the material just in noncommercial usages, provided the original work is properly cited. 
Hashemi M et al.

cal Sciences, Tehran, Iran, and the Ethics Committee of Akhtar Hospital, Shahid Beheshti University of Medical Sciences, Tehran, Iran. Information about the trial was given comprehensively, both orally and in written form, to the parents. All patients gave their written informed consents prior to their inclusion in the study, accordingly.

\subsection{Patient Selection}

This double blind clinical trial enrolled patients aged between 18 to 75 years, with a diagnosis of low back pain and unilateral lumbosacral radicular pain, due to a contained herniated degenerated disc, with a minimum of 6 months duration, not responding to medications and physical therapies. Magnetic resonance imaging (MRI) was performed to correlate the symptoms and exact disc level protrusion, or contained herniation.

Patients were excluded if they had any clinically significant or unstable medical or psychiatric illness, previous surgery on the lumbar spine, facet joint arthropathy, spinal canal stenosis, unstable neurological deficits, or cauda equina syndrome. Those who had received lumbar ESI in the past, were allergic to corticosteroids, taking anticoagulants or had bleeding diathesis, were taking systemic corticosteroids, pregnant women, or those being ESI injected within 30 days of trial, were also excluded.

Randomization was performed based on accidental numbers assigned by the computer to one of the groups of the study. Study was blinded to both sides, in which neither the patients, nor the physician evaluating, knew the group of study. Patients were given a code by the computer and the code was only known to the physician, who delivered pocket containing group of patient. Then, the code was registered as anonymous to the physician inside the operation room, who performed one of the procedures, based on the label inside the pocket accompanying the patients. After performing the procedure, the patient was evaluated by another physician, who was also blind to the code and group of patients.

\subsection{Parasagittal Interlaminar Epidural Steroid In- jection Procedure}

An 18-gauge, 3.5 inches, Tuohy needle was introduced at the level of disc lesion and advanced in a posterior to anterior direction, vertical to the body surface. After determination of the most lateral place for needle entrance, in fluoroscopy anteroposterior (AP) view, the needle was introduced into the epidural space of the affected side, using the loss-of-resistance and this parasagittal orientation of the needle was maintained throughout the procedure. Bevel direction was positioned toward lateral.

\subsection{Transforaminal Procedure}

In the TF group, a 22-gauge, 3.5 inch Quincke's needle was introduced at the level of disc lesion, using first an $\mathrm{AP}$ and, subsequently, an oblique orientation $\left(15-30^{\circ}\right)$ of the fluoroscopy C-arm to achieve the "Scotty Dog" appearance of the lumbar spine and then directed until the needle tip was in the posterior and superior aspect of the intervertebral foramen, as checked in the lateral imaging, and in line with the pedicle on AP view.

\subsection{Confirmation of Epidural Steroid Injection}

In both groups, once the needle was in position, and after negative aspiration for cerebrospinal fluid and blood, $1 \mathrm{~mL}$ contrast dye (OMNIPAQUE TM, GE Healthcare, Hatfield, UK) was injected to confirm the epidural space distribution in the AP view. This was followed by further injection of $3 \mathrm{~mL}$ of contrast under fluoroscopy, to confirm the spread of the contrast, as well as to verify that no contrast medium attained the intravascular, subarachnoid, subdural, or intra-discal spread. Lateral images were taken to evaluate the ventral epidural space. Ventral spread was defined as present if contrast travelled along the posterior longitudinal ligament or adjacent to the posterior aspect of the contiguous vertebral body at the level of needle insertion. Perineural spread and segmental spread were also noted on AP view. After epidural space confirmation, $2 \mathrm{~mL}$ of triamcinolone $(1 \mathrm{~mL}=40$ $\mathrm{mg})$, plus $2 \mathrm{~mL}$ of bupivacaine $(2 \mathrm{~mL}=10 \mathrm{mg})$ and $6 \mathrm{~mL}$ sterile normal saline were injected. All the patients were monitored for at least 30 minutes after procedure.

\subsection{Data Recording}

Sixty four patients were randomized to receive fluoroscopically guided epidural injection, through either the PIL or TF approach. Patients were evaluated for effective pain relief [numeric rating scale (NRS) $<3$ ] by $0-10$ NRS and functional improvement by Oswestry Disability In$\operatorname{dex}(6)(\mathrm{ODI}<20 \%)$ at 2 and 4 weeks. Any complications or side effects were recorded.

\section{Results}

In this prospective cohort of 64 patients with chronic low back pain, 32 patients received TF epidural injection and 32 received epidural through PIL. Demographic characteristics are listed in Table 1. There were no significant differences in age, sex, body mass index (BMI), duration of pain, pre-procedure pain score (NRS), and functional status (ODI), prior to procedure between the two groups $(\mathrm{P}>0.05)$ (Table 1$)$.

\subsection{Effective Pain Relief}

Effective pain relief (NRS < 3) was observed in 77.3\% ( $95 \%$ CI: 67-90.5\%) of patients in the parasagittal group and $74.2 \%$ (95\% CI: $62.4-89.4 \%$ ) of patients in the TF group ( $\mathrm{P}=$ 0.34 ), at 4 weeks (Figure 1). Besides, mean NRS pain score was also compared between the two groups. Mean NRS was not significantly different in the two groups, prior to epidural injection $(P>0.05)$. Mean NRS score was not significantly different in PIL group, compared to TF, at 4 weeks $(\mathrm{P}=0.19)$ (Figure 1$)$. 
Hashemi Met al.

\begin{tabular}{|c|c|c|c|}
\hline Demographic Characteristic & Parasagittal $^{\mathrm{b}}$ & $\mathbf{T F}^{\mathrm{b}}$ & PValue \\
\hline Age, $y$ & $49.2 \pm 15.5$ & $50.5 \pm 16.6$ & 0.32 \\
\hline Gender (Male/Female) & $19 / 13$ & $20 / 12$ & 0.52 \\
\hline BMI, $\mathrm{kg} / \mathrm{m}^{2}$ & $22.1 \pm 3.4$ & $21.7 \pm 3.1$ & 0.17 \\
\hline Duration of pain, mo & $8.7 \pm 6.5$ & $8.7 \pm 7.9$ & 0.67 \\
\hline Pre-procedure NRS & $7.1 \pm 2.5$ & $7.5 \pm 2.4$ & 0.13 \\
\hline Pre-procedure ODI, \% & $55.2 \pm 12.4 \%$ & $53.6 \pm 16.1 \%$ & 0.082 \\
\hline
\end{tabular}

Figure 1. Comparison of the Proportion of Patients Achieving Effective Pain Relief in Parasagittal and Midline Epidural Injection

\section{A}

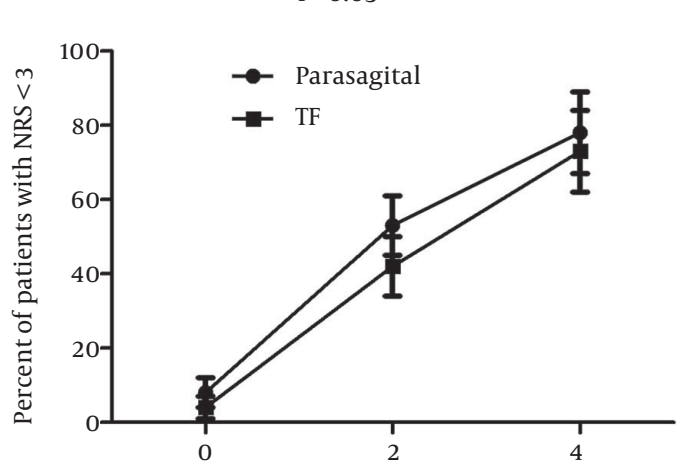

Follow-up Time (month)
B

${ }^{*} \mathrm{P}<0.05$

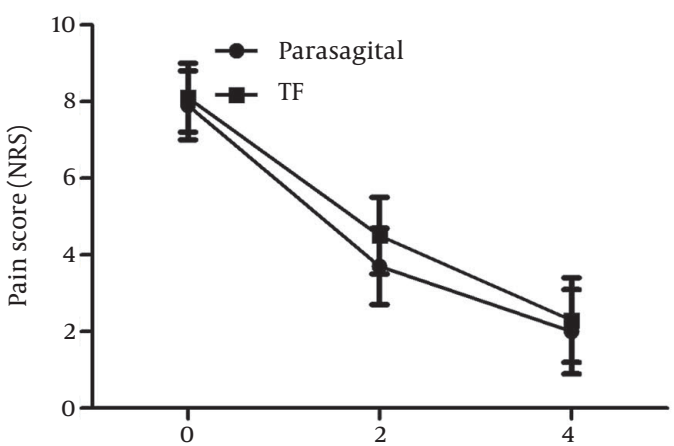

Follow-up Time (month)

The NRS < 3 at 4 weeks after PIL or TF epidural injection (left figure); Mean pain score (NRS) during follow-up time between two groups of PIL and TF epidural injection (right figure) and Abbreviations: NRS, numeric rating scale; PIL, parasagittal interlaminar; TF, transformainal.

Figure 2. Comparison of the Proportion of Patients Improving Disability Index

\section{A}

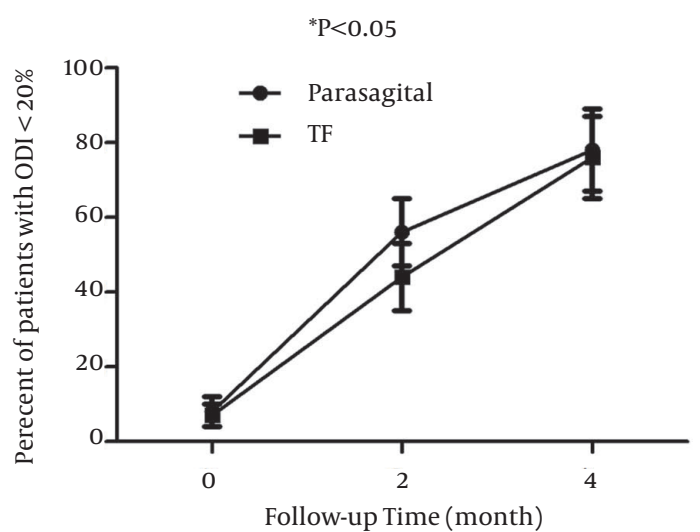

\section{B}

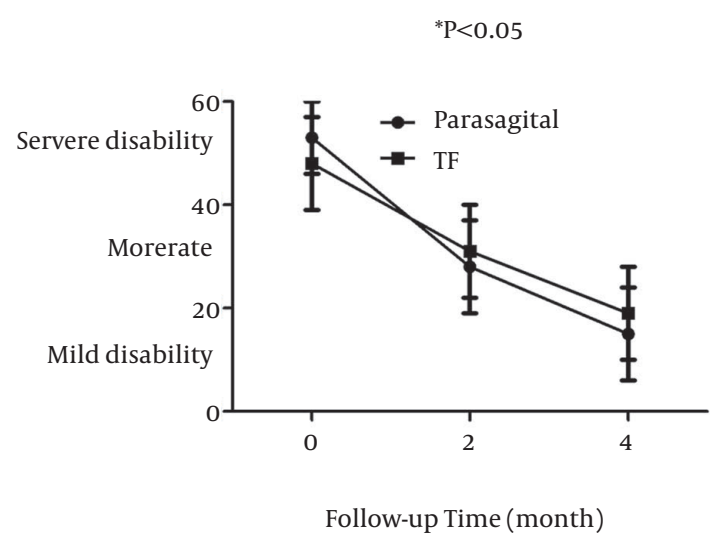

The ODI was $<20 \%$, at 2 weeks between the two groups of parasagittal and transforaminal epidural injection (left figure); Mean ODI score during the follow-up time between the two groups of parasagittal and midline epidural injection (right figure).

\subsection{Functional Improvement During Follow up Time}

Number of patients with improved disability(measured by ODI $<20 \%$ ) was not significantly different in parasagittal group ( $78 \%$ of cases), compared to the TF group (76\% of cases), at 4 weeks $(\mathrm{P}=0.21$ ) (Figure 2$)$. Besides, mean ODI score was also compared between the two groups. Mean ODI was not significantly different in the PIL compared to TF group, at 4 weeks follow up $(\mathrm{P}=0.15)$ (Figure 2). There was no adverse effect observed in any of our patients. 
Hashemi M et al.

\section{Discussion}

Intervertebral disc herniation, spinal stenosis, intervertebral disc degeneration, and failed back syndrome are the most common diagnosis of chronic radicular low back pain. Epidural injections are one of the most commonly performed interventions in managing chronic low back pain.

Among various approaches for ESI, TF is considered as target specific and more effective, compared to midline IL ESI (7). This may be due to blind administration of IL or needle placement in the dorsal space, under fluoroscopic guidance, leading to distribution of the drug to the dorsal space, rather than ventral space (8). Botwin et al. (9) evaluated lumbar IL epidural injections in epidurography pattern. They showed that dorsal contrast of flow occurred in $100 \%$ of injections; however, ventral spread of the contrast was seen only in $36 \%$ of the patients. In another study, Choi and Barbella (10), in an evaluation of contrast patterns of IL epidural injections, showed excellent spread of contrast into the nerve root and the ventral epidural space in all patients, utilizing a paramedian approach.

The advantage of TF over midline IL injections is attributed to the enhanced deposition of medication in ventral epidural space, close to the source of pain, with a smaller dose of medication (11). There is evidence suggesting that TF allows for greater ventral epidural spread of corticosteroid (12), and ventral epidural spread of corticosteroid has been associated with higher pain and functional improvements.

In our study, there was no significant difference in pain score and functional disability, after 4 weeks of follow up, between PIL and TF epidural injections. This indicates that, in both approaches, the drug is able to reach the ventral space. The existing data suggests long-term efficacy benefits are greater for TF, compared to IL (13-15). However, it remains unclear if TF ESI result in clinically or statistically significant improvements in pain and functional outcomes, compared to IL (16).

Although we did not observe any complications of TF or PIL ESI, however, other literature reviews have indicated that TF are more often implicated in complications, compared to IL ESI, including intravascular injection in up to $23 \%$ of lumbar epidural injection cases (17), which can lead to spinal cord infarction and paralysis. A meta-analysis (18) showed that TF resulted in better short-term pain improvement and fewer long-term surgical interventions than midline IL ESI. However, TF injection complications risk must be taken into consideration (19). There have been reports of pneumocephalus during TF. The complication of dural puncture is documented in the context of a lumbar TF (20). The incidence of vascular penetration, during contrast confirmed fluoroscopically guided TF epidural injections have been reported to $8.9-21.3 \%$, depending on the level of injection (21). Previous study demonstrates a high incidence of in- travascular injections in TF lumbosacral epidural injections (22). Even in severe cases, studies have presented a case of quadriparesis and brainstem herniation after selective cervical TF (23). The TF, compared to IL ESI, are associated with a 12-fold increased risk of intradiscal injection (24), which can potentially weaken the disc or lead to discitis (25). Other methods, such as intradiscal ozone injection, have been shown to have a positive effect on disk herniation (26).

In conclusion, PIL epidural injection is as effective as TF epidural injection in improving pain and functional status in patients with chronic lumbosacral low back pain, due to disc degeneration. Parasagittal approach holds the advantage of avoiding the risk of complications associated with the TF approach.

\section{Authors' Contributions}

Masoud Hashemi suggested the study design, Mohamad Reza Aryani and Gholamreza Mohseni performed data collection, data analysis and interpretation, statistics, Sirus Momenzadeh and Sajad Razavi performed critical revision and manuscript approval, Seyed Amir Mohajerani performed manuscript writing.

\section{References}

1. Chang-Chien GC, Knezevic NN, McCormickZ, Chu SK, Trescot AM Candido KD. Transforaminal versus interlaminar approaches to epidural steroid injections: a systematic review of comparative studies for lumbosacral radicular pain. Pain Physician. 2014;17(4):E509-24.

2. Benyamin RM, Manchikanti L, Parr AT, Diwan S, Singh V, Falco FJ et al. The effectiveness of lumbar interlaminar epidural injections in managing chronic low back and lower extremity pain. Pain Physician. 2012;15(4):E363-404

3. Manchikanti L, Abdi S, Atluri S, Benyamin RM, Boswell MV, Buenaventura RM, et al. An update of comprehensive evidencebased guidelines for interventional techniques in chronic spinal pain. Part II: guidance and recommendations. Pain Physician. 2013;16(2 Suppl):S49-283.

4. Desai MJ, Shah B, Sayal PK. Epidural contrast flow patterns of transforaminal epidural steroid injections stratified by commonly used final needle-tip position. Pain Med. 2011;12(6):864-70.

5. Ghai B, Vadaje KS, Wig J, Dhillon MS. Lateral parasagittal versus midline interlaminar lumbar epidural steroid injection for management of low back pain with lumbosacral radicular pain: a double-blind, randomized study. Anesth Analg. 2013;117(1):219-27.

6. Fairbank JC, Pynsent PB. The Oswestry Disability Index. Spine (Phila Pa 1976). 2000;25(22):2940-52.

7. Pinto RZ, Maher CG, Ferreira ML, Hancock M, Oliveira VC, McLachlan AJ, et al. Epidural corticosteroid injections in the management of sciatica: a systematic review and meta-analysis. Ann Intern Med. 2012;157(12):865-77.

8. Schaufele MK, Hatch L, Jones W. Interlaminar versus transforaminal epidural injections for the treatment of symptomatic lumbar intervertebral disc herniations. Pain Physician. 2006;9(4):361-6.

9. Botwin KP, Natalicchio J, Hanna A. Fluoroscopic guided lumbar interlaminar epidural injections: a prospective evaluation of epidurography contrast patterns and anatomical review of the epidural space. Pain Physician. 2004;7(1):77-80.

10. Choi YK, Barbella JD. Evaluation of epidurographic contrast patterns with fluoroscopic-guided lumbar interlaminar ventral epidural injection. Pain Pract. 2009;9(4):275-81.

11. Lutz GE, Vad VB, Wisneski RJ. Fluoroscopic transforaminal lumbar epidural steroids: an outcome study. Arch Phys Med Rehabil. 1998;79(11):1362-6. 
12. Ackerman W3, Ahmad M. The efficacy of lumbar epidural steroid injections in patients with lumbar disc herniations. Anesth Analg. 2007;104(5):1217-22.

13. Riew KD, Yin Y, Gilula L, Bridwell KH, Lenke LG, Lauryssen C, et al. The effect of nerve-root injections on the need for operative treatment of lumbar radicular pain. A prospective, randomized, controlled, double-blind study. J Bone Joint Surg Am. 2000;82A(11):1589-93.

14. Fantini GA, Pawar AY. Access related complications during anterior exposure of the lumbar spine. World J Orthop. 2013;4(1):19-23.

15. Manchikanti L, Boswell MV, Singh V, Benyamin RM, Fellows B, Abdi S, et al. Comprehensive evidence-based guidelines for interventional techniques in the management of chronic spinal pain. Pain Physician. 2009;12(4):699-802.

16. Candido KD, Raghavendra MS, Chinthagada M, Badiee S, Trepashko DW. A prospective evaluation of iodinated contrast flow patterns with fluoroscopically guided lumbar epidural steroid injections: the lateral parasagittal interlaminar epidural approach versus the transforaminal epidural approach. Anesth Analg. 2008;106(2):638-44.

17. Nahm FS, Lee CJ, Lee SH, Kim TH, Sim WS, Cho HS, et al. Risk of intravascular injection in transforaminal epidural injections. Anaesthesia. 2010;65(9):917-21.

18. Quraishi NA. Transforaminal injection of corticosteroids for lumbar radiculopathy: systematic review and meta-analysis. Eur Spine J. 2012;21(2):214-9.

19. Kolstad F, Leivseth G, Nygaard OP. Transforaminal steroid injec- tions in the treatment of cervical radiculopathy. A prospective outcome study. Acta Neurochir(Wien). 2005;147(10):1065-70.

20. Goodman BS, Bayazitoglu M, Mallempati S, Noble BR, Geffen JF. Dural puncture and subdural injection: a complication of lumbar transforaminal epidural injections. Pain Physician. 2007;10(5):697-705.

21. Smuck M, Fuller BJ, Yoder B, Huerta J. Incidence of simultaneous epidural and vascular injection during lumbosacral transforaminal epidural injections. Spine J. 2007;7(1):79-82.

22. Furman MB, O'Brien EM, Zgleszewski TM. Incidence of intravascular penetration in transforaminal lumbosacral epidural steroid injections. Spine (Phila Pa 1976). 2000;25(20):2628-32.

23. Tiso RL, Cutler T, Catania JA, Whalen K. Adverse central nervous system sequelae after selective transforaminal block: the role of corticosteroids. Spine J. 2004;4(4):468-74.

24. Cohen SP, Maine DN, Shockey SM, Kudchadkar S, Griffith S. Inadvertent disk injection during transforaminal epidural steroid injection: steps for prevention and management. Pain Med. 2008;9(6):688-94.

25. Candido KD, Katz JA, Chinthagada M, McCarthy RA, Knezevic NN Incidence of intradiscal injection during lumbar fluoroscopically guided transforaminal and interlaminar epidural steroid injections. Anesth Analg. 2010;110(5):1464-7.

26. Hashemi M, Poorfarokh M, Mohajerani SA, Jalili P, Akhyani V, Barikani A, et al. Injection of intradiscal 02-03 to reduce pain and disability of patients with low back pain due to prolapsed lumbar disk. Anesth Pain Med. 2014;4(5):e19206. 